\title{
THE USAGE OF BLACKBOARD LEARN COMMUNITY OF PRACTICE IN HIGHER EDUCATION INSTITUTIONS IN UAE
}

\author{
Lina Daouk and Nafeth Hamdi Al Hashlamoun \\ Higher Colleges of Technology \\ P.O.Box: 41012, Abu Dhabi, UAE
}

\begin{abstract}
UAE Higher education institutions were among the first institutions in the Middle East to adopt Blackboard Learn (BBLearn) as the learning management system for their e-learning activities. Regardless of the large investments spent of BBLearn, the adoption of this system among the faculty is still slow. This qualitative case study research aimed to investigate the need for the creation of a BBLearn community of practice $(\mathrm{CoP})$ in a public higher education institution in the United Arab Emirates, its anticipated benefits and its positive impact on increasing the adoption of BBLearn among the computer department faculty. A qualitative case study research methodology was used, and data was collected from faculty of the public higher education institution. The findings revealed that the faculty support the creation of a BBLearn CoP and they identified its anticipated benefits and listed them. The findings also confirmed that the creation of a BBLearn CoP will have positive impact on the adoption of BBLearn among the computer department faculty. This study confirmed the importance of communities of practice and their roles in sharing and advancing knowledge. It also revealed the need to create a BBLearn CoP to address the slow adoption of BBLearn among faculty.
\end{abstract}

\section{KEYWORDS}

Community of Practice, $\mathrm{CoP}$ in a Public Higher Education Institution in UAE

\section{INTRODUCTION}

Over the last decades, the investment of higher education institutions (HEI) in e-learning instructional technologies have witnessed a continuous steady increase (Gunn, 2010). Similar to other business organizations, HEI have realized that the key to success in the new digital age is to leverage the benefits from e-learning instructional technologies (Wang, Wang, \& Shee, 2007). It is commonly understood that e-learning instructional technologies refer to the usage of information technology in learning and teaching (Czerniewicz \& Brown, 2009; Salmon, 2005). Following the international e-learning trends, the investment of United Arab Emirates (UAE) HEI in e-learning instructional technologies witnessed a similar increase over the last decades (Vrazalic, Macgregor, Behl, \& Fitzgerald, 2009) with millions of dollars being spent on managing e-learning platforms (Daghfous \& Barkhi, 2009; Kats, 2010).

BBLearn is one of the most commonly used LMS in HEI in UAE ("Blackboard | Education Technology \& Services," n.d.-a). While most of UAE HEI have reported an increase in the implementation of BBLearn, the lack of effective professional development for faculty has been identified by many researchers as one of the main reasons for the slow adoption process of BBLearn among faculty (Abdullah \& Ward, 2016; Kassim, Jailani, Hairuddin, \& Zamzuri, 2012; Mirza \& Al-Abdulkareem, 2011; Tarhini, Hone, Liu, \& Tarhini, 2017; Wang et al., 2007).

The concept of CoP was first developed by Jean Lave and Etienne Wenger (Lave \& Wenger, 1998). Wenger (2000) in his book "Communities of practice: The key to knowledge strategy" stated that one of the main reasons for CoPs to emerge is the existence of common interest or problem among a collection of people. The rate of adoption of BBLearn among the faculty in in the computer department of public higher education institution is slow when compared to the investment committed by our college. In this paper, I attempt to study the need for the creation of a BBLearn $\mathrm{CoP}$ at the public higher education institution using a case study research methodology. 


\section{BODY OF PAPER}

\subsection{Research Problem}

Considering the large investment in BBLearn and its slow adoption among the computer department faculty, the issue of creating a BBLearn community of practice for the faculty in the higher education institution to address this problem merits special attention (Dlamini, 2015; Vrazalic et al., 2009).

\subsection{Purpose of the Study}

The purpose of this qualitative research is to investigate the need for the creation of a BBLearn CoP in the institution, its anticipated benefits and its positive impact on increasing the adoption of BBLearn among the faculty. To achieve this objective, a case study research methodology approach will be conducted in the institution. Four of the faculties will be interviewed and the collected data along with the literature review will be used to answer the research questions. The institution is considered to be part of the HEI in UAE with around 23,000 full time students in more than one campus serving all emirates of UAE and was among the first institutions to implement e-learning systems.

\subsection{Research Questions}

The overarching research question of this study is to investigate the need for the creation of a community of practice for Blackboard Learn from the perspective of the computer department faculty and the anticipated benefits. The particular research questions that will be addressed in this study are:

RQ1. What do the faculty of the institution believe are the anticipated benefits from the creation of a BBLearn CoP?

RQ2. How should the BBLearn CoP creation be managed?

RQ3. How will the creation of the BBLearn CoP affect the adoption of BBLearn among faculty?

\subsection{Literature Review}

This literature review aims to provide an overview on CoPs and their corresponding social learning theory. The literature review is organized as follows: the characteristics and benefits of CoPs are examined first. The factors that affect the success and failure of CoPs are examined after that. This is followed by a discussion about the need for e-learning CoPs among the faculty of HEI and their anticipated benefits. The literature review concludes by identifying the literature gaps on e-learning CoPs.

\subsubsection{Communities of Practice: Characteristics and Benefits}

A community of practice (CoP) evolves when a group of people who have a common interest in a particular domain come together or it can be created based on a specific goal of sharing information and experiences between group members (Cho, 2016). During this process, CoP members learn from each other which create opportunities for them to advance and grow professionally and personally (Wenger, McDermott, \& Snyder, 2002). Probst and Borzillo (2008) stated that a CoP is a specific form of intra-organizational networks. Members use these specific intra-organizational networks for the development and sharing of knowledge and practices across organizational departments. McDermott (1999) called these specific intra-organizational networks in organizations as cross functional teams. In addition, Wenger et al. (2002) stated that CoP should be created voluntary. This voluntary structure of CoP should be able to generate excitement, relevance and more important value to engage members and attract new ones. Furthermore, Hearn and White (2009) stated that a CoP creates a specific environment that allow members to reflect, interpret and give their feedback enriching the relationships between the members which lead to generating and liking knowledge, policy and practice.

The concept of CoP was developed by Jean Lave and Etienne Wenger (Lave \& Wenger, 1998; Etienne Wenger, 2000) as a basis of a social theory of learning (Eckert, 2006). The CoP term was invented by Jean Lave and Etienne Wenger while they were investigating apprenticeship as a learning model (Wenger, 2006). 
Wenger (2006) stated that there are three main characteristics that are essential to create a CoP: the domain, community and practice. The domain is what distinguish a CoP from a group of friends of colleagues coming together. Membership implies a commitment to the domain and hence members have a shared competence that distinguishes them from other people (Wenger, 2006). The community indicates that members pursue their interest in their domain. Members engage in joint activities and discussion, work with each other, and share information and experiences. The practice implies that members are practitioners and not simply group of people who share a common interest. They share stories, experiences, tools, ways of addressing common recurring problems related to their domain. Cambridge, Kaplan and Suter (2005) listed four main benefits that member of a CoP expect: Connection, shared context, dialogue and collaborative processes. Jakovljevic (2012) stated that one of the main characteristics of a CoP is that it must be psychologically safe and secure environment. The author maintains that $\mathrm{CoP}$ creates a safe environment for members to drop their fear of criticism, ridicule and retrenchment and unleash their creativity to address common domain problems.

In summary, the main characteristics of a $\mathrm{CoP}$ are the domain, the community, the practice, and the safe innovative environment. The main benefits are: connections, shared context, dialogue and collaborative processes.

\subsubsection{Communities of Practice: Success and Failures Factors}

Probst and Borzillo (2008) investigated 57 CoPs in major European and US companies such as Siemens, Oracle, IBM, Holcim, Mazda, eCoopers, SwissRe, and the world bank to identify the antecedents of their success and failures. The authors listed three major differences between CoPs and regular project team, operational teams, or purely informal network. The first difference is that in CoPs members' roles are not assigned formally and the delineations of these roles are not even clear. Secondly, CoPs members have no formal contractual obligations of any sort. Thirdly, CoPs members share a common interest to develop their practices in their specific domain whereas in other business team structures the members' interest will only last as long as its members find it beneficial to the business. Probst and Borzillo (2008) identified ten commandments of $\mathrm{CoP}$ governance that lead to the successful and sustainable development of CoPs and five major reasons for CoPs.

Van Rensburg, Botma, Heyns, and Coetzee (2016) explored the experiences of a group of nurses who started a support group and transformed it to a successful community of practice. Using a case study design guided by the theory of action (Allen, 1984; Coleman, 1986), the authors identified four themes that illuminated and explicated the experiences of the group of nurses, namely shared domain of interest, informal network, formal work group and community of practice. The four themes identified by Van Rensburg et al. (2016) support the ten commandments identified by Probst and Borzillo (2008) particularly having clear strategic objectives and a governance committee with sponsors and CoP leaders to guide the CoP.

Liberatore, Bowkett, Macleod, Spurr, and Longnecker, (2018) investigated the factors that affect the creation of a successful social media CoP for the New Zealand Garden Bird. The authors used a case study design to investigate seven principles for cultivating a successful social media CoP which are: (1) design for evolution, (2) foster open dialogue between inside and outside perspectives, (3) provide public and private community space, (4) enable multiple levels of participations, (5) focus on value, (6) combine familiarities and excitement, and (7) create a rhythm for the community. The seven principles identified by Liberatore et al. (2018) supports the findings of Probst and Borzillo (2008) particularly promoting access to outsiders to general new interests.

Kirkman, Mathieu, Cordery, Rosen, and Kukenberger (2011) developed and empirically tested a CoP effective model using data from $32 \mathrm{CoPs}$ in a United Stated based firms. The authors concluded that the following factors have positive impact of the effectiveness of CoPs: (1) the existence of external community leaders, (2) empowerment, (3) recognition of CoPs as "core" by the organization, and (4) task independence. Kirkman et al. (2011) empirical study confirms again the finding of Probst and Borzillo (2008).

In summary, the antecedents identified by Probst and Borzillo (2008) and supported by Van Rensburg et al. (2016), Liberatore et al. (2018), and Kirkman et al. (2011) provide a summary of the factors that affect the success and failures of CoPs.

\subsubsection{Communities of Practice and e-Learning}

Using a case study research design, Chang, Chen, and Li (2008) investigated the benefits of an e-learning CoP for a programming course at their university. Chang et al. (2008) argued for the construction of a web-based 
coursework environment with the aim to promote knowledge sharing, improve the quality of students' coursework and advance learning performance. Again using a case study research design, Cho, (2016) studied the benefits of a bilingual online CoP for pre-service teachers. The findings of this empirical study revealed that mutual engagement, joint enterprise, and shared repertoire were among the features that have positive impact on the creating a beneficial learning experience for these pre-service teachers. Similar to the previous two studies, Clarke (2009) used a case study design to investigate the outcomes of a professional online district CoP of student teachers' professional learning online. Clarke (2009) work empirically shows the power of e-learning CoPs of teachers to create new learning curriculums that recognize the potential of virtual learning environments for their students.

In summary, Chang et al. (2008), Cho, (2016) and Clarke (2009) presented the features and benefits of e-learning CoPs of teachers. Particularly, Clarke (2009) revealed a new powerful advantage of e-learning teachers' CoPs which is the creation of specific curriculum for virtual learning environment.

\subsubsection{A Brief Description of the Gaps}

Jean Lave and Etienne Wenger stated that CoPs are everywhere, and that people are involved in a number of them formally or informally. The commandments stated by Probst and Borzillo (2008) formed a governance for successful CoP and researchers like Chang et al. (2008), Cho, (2016) and Clarke (2009) presented the features and benefits of e-learning CoPs. However, there is limited research on the learning management systems e-learning CoPs and in particular about BlackBoard CoPs. In addition, the anticipated benefits from a BBLearn CoP in HEI has not yet been fully explored by researchers. I am confident that this case study will support bridging some of the gaps identified.

\subsection{Theoretical Framework}

The community of practice theory as developed by Jean Lave and Etienne Wenger (Lave \& Wenger, 1998) provides a theoretical guidance that was used to direct this case study. The attributes of the three main conceptual themes of Wenger (2006): the domain, community and practice were used as a conceptual lens to guide the development of my case study research as presented in Figure 1.

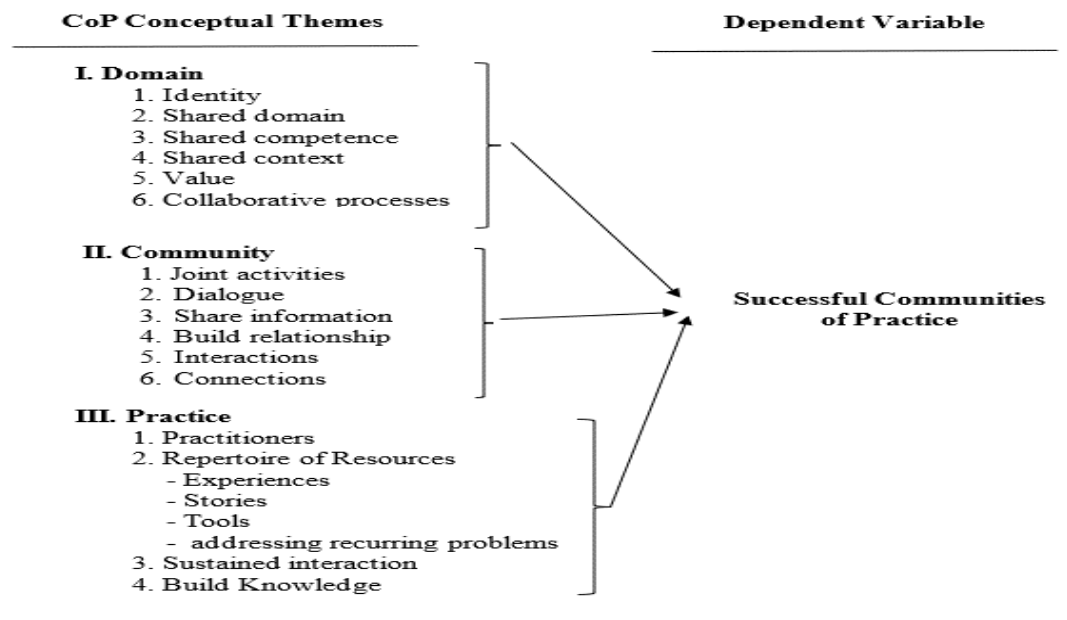

Figure 1. Wenger (2006) communities of practice conceptual themes

\subsection{Epistemology and Ontology}

Epistemology and ontology are sometimes used interchangeability (Goodson \& Phillimore, 2004) but as a researcher I understand fully the difference between them where epistemology is about the way I know things while the ontology is about is what things are. This research is a mini qualitative case study research and hence my ontology is to find out what are the things by analyzing participants answers from the interviews and conducting a literature review about e-learning CoPs. I will continue to have an epistemological stance that by 
conducting qualitative research I will be able to understand and increase my knowledge about things. This research follows the positivism paradigm where my role is to analyze the data collected and report the findings objectively.

\subsection{Research Methodology}

The research methodology used in this paper is a case study design. A case study design permits the examining of complex issues and contemporary real-life situations. Researchers have used case study research designs across many disciplines and in particula social scientists used case study designs for their qualitative research to provide a base for the application and extension of ideas (Creswell, 2014; Yin, 2013) and this is the case of this research.

\subsubsection{NVivo Coding}

One level of coding was used to code the participants' answers in NVivo. A node was created for each question with the answers of the four participants together. Where possible, two queries were run on each node: word frequency queries and text search queries. On all nodes, one minimum text search query using the attributes of Wenger (2006) was executed and where possible a word frequency query was used.

\subsection{Data Collection and Analysis}

Data was collected from one source which is the open-ended face to face interviews. 10 questions were used in the interviews. Yin (2013) stated that interviews are listed among the most important source of data in case study designs. There are many types of interviews that can be used in case study (Leedy \& Ormrod, 2010). The most common types are those that are open ended and semi structured. The design of the interviewing questions was of semi-structured types as described by Yin (2013) with few central questions. The Semi structured design allowed me to questions participants about facts and their opinions and to follow up on certain answers. All of the interviews conducted took maximum one hour to complete. All data collected were text generated from the immediate transcription of the participants' answers.

Four of my colleagues agreed to participate in this research. Participants were all from the computer department who are currently involved in developing courses using BBLearn. The participants were two male and two female faculty. Two of them were lecturers and two were assistant professors. This reflects the overall gender distribution in the department that is equally split between male and female reflecting the nature of the Abu Dhabi Women's College. A linear hierarchical approach was used to analyze the collected data by building from bottom to the top with multiple interactions between the steps (Patton, 2001; Shank, 2005). In the first step, I organized and prepared the collected data for analysis. I read through all the collected data and reflected on its overall meaning in the second step. In the third step, I started a coding process using the themes presented by Wenger (2006). I used the NVivo ("NVivo," n.d.) software to analyze he collected data.

\subsection{Quality and Trustworthiness of the Study/Findings}

In order to improve the quality and trustworthiness of the collected data, the four colleagues were selected from three different subdivisions in the computer department. While triangulation of evidences by collecting data from other sources like documents, policies and artifacts was not possible due to the time frame of this research, the selection of colleagues from different sub-division in the computer department combined with the literature review on the CoPs should be enough to cover the quality and trustworthiness of this research.

\subsection{Ethical Issues and Limitations}

All Data collected will be used only for the purpose of this research and will not be shared with anyone. No personal information will be identified. I will keep the digital data for three years and then it will be deleted. This research is under the exempt research type as described by Cozby (2008) since the risk to harm the participants is not greater than the risk they encountered during my normal working activities. 


\subsection{Findings}

This section reports the findings of the interviews that were conducted with four faculty of the computer department. The interviews were conducted using interviews of 10 questions. The first six questions covered the three conceptual themes as presented by Wenger (2006). The last four questions covered the proposed way to manage the BBLearn CoP and any foreseen barriers.

\subsubsection{Sample Demographics}

The following was collected from the participants to form the demographic profile of the participants: age, gender, total years of experience, BBLearn usage experience, job titles, department / subdivision, and education. The participants are referred with their alias as P1, P2, P3, and P4. The sample demographics are summarized in table 1 below.

Table 1. Summary of the sample demographics

\begin{tabular}{|l|c|c|c|c|c|c|c|}
\hline & Age & Gender & $\begin{array}{c}\text { Total } \\
\text { experience }\end{array}$ & $\begin{array}{c}\text { BBL } \\
\text { experience }\end{array}$ & Job Title & Department & Education \\
\hline P1 & 45 & Male & 16 & 3 & $\begin{array}{c}\text { Assistant } \\
\text { Professor }\end{array}$ & $\begin{array}{c}\text { CIS / Security and } \\
\text { Forensics }\end{array}$ & $\mathrm{PhD}$ \\
\hline P2 & 48 & Male & 15 & 3 & $\begin{array}{c}\text { Assistant } \\
\text { Professor }\end{array}$ & $\begin{array}{c}\text { CIS / Application } \\
\text { development }\end{array}$ & $\mathrm{PhD}$ \\
\hline P3 & 44 & Female & 14 & 2 & Lecturer & $\begin{array}{c}\text { CIS/ Business } \\
\text { Solution }\end{array}$ & MS \\
\hline P4 & 51 & Female & 20 & 4 & Lecturer & $\begin{array}{c}\text { CIS / Business } \\
\text { Solution }\end{array}$ & MS \\
\hline
\end{tabular}

Note: This table summarizes the sample demographics of the 4 participants.

Table 2 summarizes the descriptive statistics of the sample demographics.

Table 2. Descriptive statistics of the sample demographics

\begin{tabular}{|l|r|r|r|r|r|}
\hline \multicolumn{9}{|c|}{ Descriptive statistics } \\
\hline Age & \multicolumn{1}{|c|}{ N } & \multicolumn{1}{c|}{ Minimum } & \multicolumn{1}{c|}{ Maximum } & \multicolumn{1}{c|}{ Mean } & \multicolumn{1}{c|}{ Standard deviation } \\
\hline Total experience & $\underline{4}$ & $\underline{4}$ & $\underline{51}$ & $\underline{47}$ & $\underline{3}$ \\
\hline BBL experience & $\underline{4}$ & $\underline{14}$ & $\underline{20}$ & $\underline{16}$ & $\underline{0.8}$ \\
\hline Valid N (list wise) & $\underline{4}$ & $\underline{4}$ & $\underline{4}$ & $\underline{2.9}$ & \\
\hline
\end{tabular}

The mean of the age of the participants is 47 and the mean of the total years of teaching experiences is 16 which reflect a high level of maturity of the participants as professional instructors with years of experience who can provide reliable and up to date information about their experiences in e-learning and BBLearn. With 2.9 years of mean experience of BBLearn usage, this again gives a high level of confidence that the participants have enough relevant years of experiences in using BBLearn.

\subsubsection{Analysis of the Interview Answers}

\section{Question 1: What do you think a community of practice for Blackboard learn is all about?}

All four participants answered the first question with details. Each member gave his opinion about what a BBLearn CoP is about. Starting from the responses of the third participant, the understanding of BBLearn CoP notion started to repeat itself. This is a good indication that saturation was achieved, and the participants have reached a common notion about what is BBLearn is all about.

The answers of the first question received from the 4 participants were coded in NVivo software. Table 3 lists the results of the top 10 frequently used words in the complete answers of question 1. 
Table 3. Top 10 used words in the answers of question 1

\begin{tabular}{|l|l|l|l|l|}
\hline Word & Length & Count & Weighted Percentage (\%) & Similar Words \\
\hline participant & 11 & 43 & 2.55 & participant, participate, participation \\
\hline community & 9 & 40 & 2.37 & $\begin{array}{l}\text { communication, communities, } \\
\text { community }\end{array}$ \\
\hline cop & 3 & 40 & 2.37 & cop, cops \\
\hline learn & 5 & 37 & 2.19 & learn, learned, learning, learning' \\
\hline members & 7 & 34 & 2.02 & member, members, members' \\
\hline share & 5 & 26 & 1.54 & share, shared, sharing \\
\hline people & 6 & 25 & 1.48 & people \\
\hline different & 9 & 23 & 1.36 & difference, different \\
\hline practice & 8 & 23 & 1.36 & practice, practices, practicing \\
\hline experience & 10 & 21 & 1.25 & discuss, discussion, discussions \\
\hline discussion & 10 & 20 & 1.19 &
\end{tabular}

The words participation, learn, share, practice, experience and discussion were among the most repeated used words by the four participants in describing the BBlearn community of practice. The result of this query are in line with the attributes listed by Wenger (2006) about the characteristics of CoPs.

A text search query on the word $\mathrm{CoP}$ in the participants answers for question 1 provide a summary of what the participants think are the main characteristics of a BBLearn CoP. The results of this query are shown in figure 2 below.

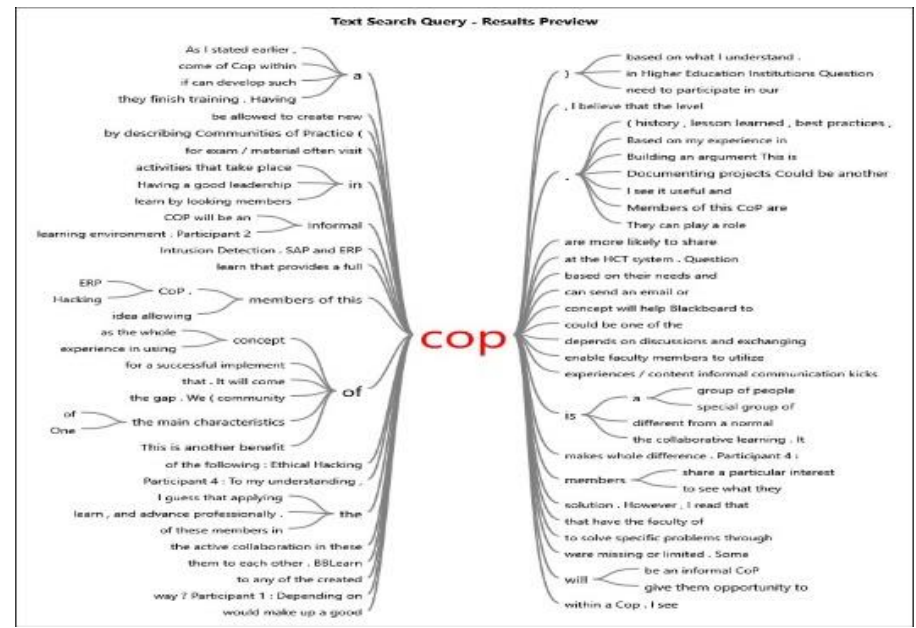

Figure 2. The text search results on word $C o P$ and its relationship with the other most repeated words used in the complete answers of question 1

Question 2: How do you know that a community of practice for Blackboard Learn at our college will provide you with the professional development you need and in an accurate way?

All the four participants answered this question with full details. 280 words were used to answer this question by the 4 participants. Collaborative learning and sharing resources and learning from each other were among the most repeated words on how the BBLearn CoP will provide the professional development needed. A text search query using NVivo on the word learn in the participants answers for question 2 provide a summary on how collaborative learning in the BBLearn $\mathrm{CoP}$ will provide the professional development needed for faculty to increase their usage of BBLearn. The text search relationship between the word learn and other words in the answers is presented in figure 3 below. 


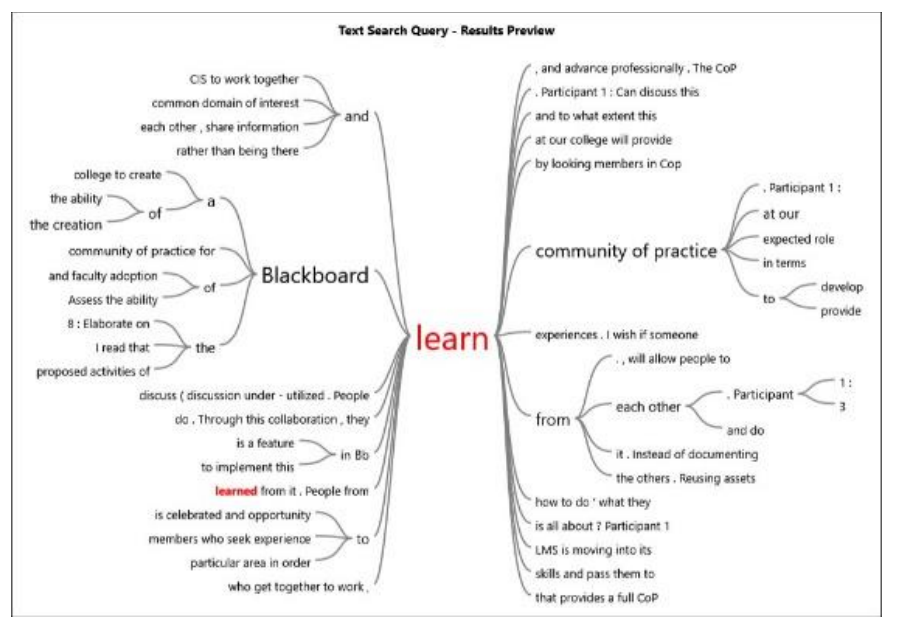

Figure 3. The text search results on word learn and its relationship with the other most repeated words used in the complete answers of question 2

The analysis of questions 3 to 10 followed the same procedure used in the analysis of questions 1 and 2 .

Question 3: Evaluate the following proposed activities of the Blackboard Learn community of practice in terms of addressing the particular needs for your job.

All four participants answered this question. Three of the four participants considered all the listed activities as beneficial to their work. Only one participant thought that two of the activities are not applicable to his domain. Apart from that, all participants agreed that the proposed activities of BBLearn will address their needs for their jobs. A summary of the words used by all the participants to evaluate the proposed activities is presented in table 4.

Table 4. Summary of the words used to evaluate BBLearn proposed activities

\begin{tabular}{|c|c|}
\hline Proposed activities & Words used by participants \\
\hline Problem solving & Great idea, efficient, success \\
\hline Request for information & Needed, helpful, accessible \\
\hline Seeking experience & Learning, repertoire, sharing \\
\hline Re-using assets & Best practice, knowledge \\
\hline Coordination and synergy & Needed, very important, sharing knowledge \\
\hline Building an argument & Natural, focused, a place to voice opinions \\
\hline Growing confidence & Not applicable, highly important, good. \\
\hline Discussion and developments & Needed, required \\
\hline Documenting projects & Good place, important activity, supportive culture \\
\hline Visits mapping knowledge and identifying gaps & $\begin{array}{l}\text { Not applicable, relevant and helpful, useful in bridging } \\
\text { gaps. }\end{array}$ \\
\hline
\end{tabular}

Question 4: Elaborate on the existence of a shared domain of interest between the faculty of our department to create a Blackboard Learn community of practice.

All participants answered this question and provided full details. From the answers of the four participants we noticed that they all agree on the existence of a shared domain of interest between the faculty of the computer department at the public higher education institution to create a BBLearn CoP. A query of the frequently used word in the complete four answers received from the participants using NVivo reveals that the word practice with its stemmed words and its synonyms was repeated 86 times. In addition, the words experience, share, collaborative, and value were repeated $62,47,14$, and 7 respectively. This is a clear indication that the most repeated words in answering this question are the attributes listed by Wenger (2006) in describing the shared domain of CoPs. The results of the query as produced by NVivo are presented in table 5. 
Table 5. The frequency of the most repeated words in the answers of question 4

\begin{tabular}{|l|l|l|l|l|}
\hline Word & Length & Count & Weighted Percentage (\%) & Similar Words \\
\hline Practice & 8 & 86 & 2.50 & $\begin{array}{l}\text { applying, do', good, much, practice, } \\
\text { practices, practicing, skill, skilled, } \\
\text { skillful, skills, use, used, useful, } \\
\text { using }\end{array}$ \\
\hline Share & 5 & 47 & 1.97 & $\begin{array}{l}\text { contribution, part, share, shared, } \\
\text { sharing }\end{array}$ \\
\hline Experience & 10 & 62 & 1.89 & $\begin{array}{l}\text { experience, experiences, feel, get, } \\
\text { know, knowing, receive, see }\end{array}$ \\
\hline collaboration & 13 & 14 & 0.65 & $\begin{array}{l}\text { collaborate, collaboration, } \\
\text { collaborative }\end{array}$ \\
\hline Value & 5 & 7 & 0.30 & $\begin{array}{l}\text { assess, assessing, evaluate, } \\
\text { measure, value, values }\end{array}$ \\
\hline
\end{tabular}

Question 5: Describe the ability of a Blackboard Learn community of practice to provide its member with a space to interact, help each other, share information and learn from each other.

The answers received for this question showed different opinions between the participants about the BBLean capability to provide a space for the members to interact. Two participants did not know if such capabilities exist in BBLearn, and the other two though that discussion boards and other similar features in BBLearn can provide the needed CoP features. Overall, there is agreement between the participants that if BBLearn cannot provide the needed CoP capabilities in term of a space to interact to share information, at least it can provide them with a private space to share information among faculty and learn from each other.

Question 6: Assess the ability of Blackboard Learn community of practice to develop a shared practice that help members to share their repertoire of resources, experiences, stories, tools, and their ways of addressing recurring problems.

All participants answered this question with full details. There is common agreement between participants on the positive ability of BBLearn CoP to develop a shared practice among its members. The participants listed Loyalty, feel of belonging, achievement, recognizing of efforts, management support among the shard practice attributes that will support the members. A text search query using NVivo on the word practice in the participants answers for question 6 provide a summary on the ability of BBLearn CoP to develop a shared practice among the faculty of the computer department in the public higher education institution. The text search relationship between the word practice and other words in the answers is presented in figure 4 below.

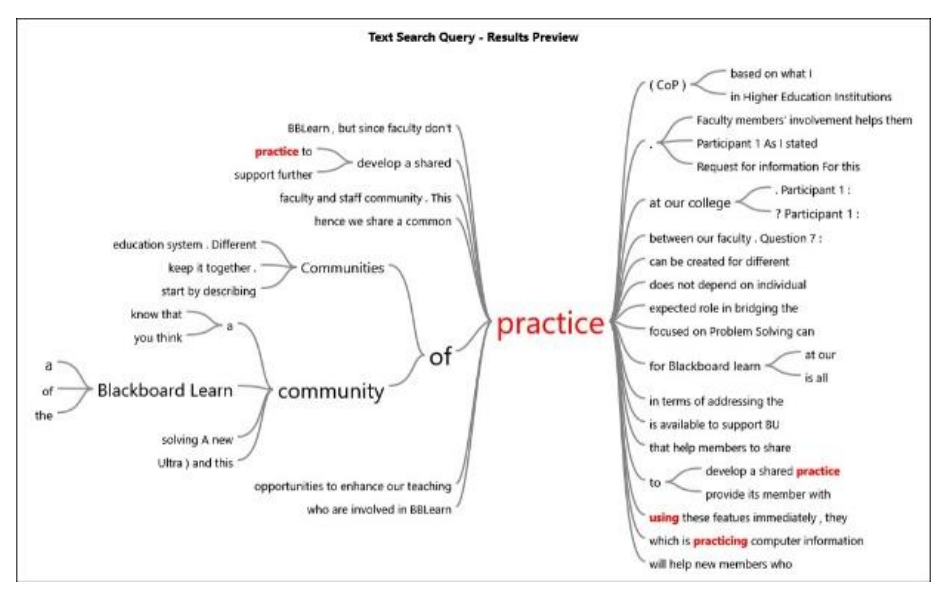

Figure 4. The text search results on word practice and its relationship with the other most repeated words used in the complete answers of question 6

Question 7: Delineate on how to manage the creation of a Blackboard Learn community of practice at our college.

Different responses were received on the possible ways to manage the BBLearn CoP. Two participants considered this as part of the management role and stated that the management of the CoP can be done by the 
educational department at the college. The other two participants stated that this should be managed by the members of the $\mathrm{CoP}$ and one participants acknowledged the role of external members and sponsors in the management of the CoP. Overall, we can conclude that the answers received about the management of the BBLearn are in line with the commandments identified by Probst and Borzillo (2008).

Question 8: Elaborate on the Blackboard Learn community of practice expected role in bridging the gap between the professional training and faculty adoption of Blackboard Learn.

There is agreement between the four participants on the positive role that the BBLearn CoP will play in bridging the gap between the professional training and the adoption of Blackboard learn at the college. Participants shared the opinion that while the professional development they receive provide them with the skills they need, the lack of practice and the lack of a place to share information and request further help are among the main reasons for the slow adoption among faculty. The participants agreed and confirmed that a BBLearn CoP will be able to bridge that gap by complementing the professional development they receive and provide its member with a place to share and advance knowledge.

Question 9: Can you please explain what do you believe are the barriers to the creation of a Blackboard Learn community of practice at our college?

The participants answered this question with full details. They listed culture and environment among the most difficult barrier to the creation of the BBLearn CoP. We did not have time to elaborate on these barriers, but one participants stated openness and another stated management support and a third participant stated that this might be the job of the management. We can conclude form the responses received, that the participants are fully aware of the barriers and this show an alignment of their answers between understanding first the need of this CoP, listing its benefits after that and finally identifying the barriers.

Question 10: As a faculty at our college, how are you planning to overcome the barriers to the creation of a Blackboard Learn community of practice at our college?

All participants answered this question by listing at least one solution to overcome the barriers. Solutions received were to address the barriers listed above. Two participants stated that changing the culture as a solution. Another participant stated involvement of management and recognizing efforts of faculty as a possible solution. The fourth participants stated faculty should create the BBLearn CoP regardless and work on solving the barriers as they arise.

\section{CONCLUSION}

This case study research revealed the existence of a collective need among the faculty of the computer department of the public HEI to establish a BBLearn community of practice. It confirmed that the faculty of the computer department of the public HEI use the attributes of the three themes presented by Wenger (2006) to measure the anticipated benefits from the creation of the BBLearn. Particularly this case study established the existence of a common domain, a sense of community and a shared practice among the faculty of the computer department of the public HEI. In addition, this case study revealed that while the faculty of the public HEI don't have a clear idea on how this BBLearn CoP will be managed, they understand the barriers to the creation of this CoP and they have a plan to address them.

This case study research revealed the existence of a shared domain among the faculty of the the computer department of the public HEI. The faculty of computer department believe that they have a common identify for their shared domain. The faculty implied a commitment to their domain and even suggested sub-committees for the proposed BBLearn CoP such as a security related one and an SAP one. The computer department of the public HEI were able to identify a shared competence that distinguishes them from the rest of the faculty at the college. Finally, the case study confirmed that the faculty of the computer department of the public HEI value their collective competence and are ready to learn from each other.

This case study research also confirmed the existence of a community feeling among the faculty of the computer department. Faculty are engaged in joint activities, they value dialogue and they understand the importance of sharing BBLearn information. This research confirmed the existence of healthy interactions and 
connections among the faculty of the computer department that is necessary to create a community for the faculty who are pursuing their interest in their common domain.

In addition, this case study confirmed the practice theme among the faculty of the computer department. They don't only have a common domain and feeling of community, but also they are practitioners. In working with BBLearn, the computer department faculty develop a shared repertoire of resources such as experiences, stories, tools, way of addressing recurring problem, and problem-solving techniques. This research confirmed that the computer department faculty have a shared practice. In summary, this case study research confirmed the existence of the three themes that support the need for creating successful CoP as presented by Wenger (2006). This addresses the purpose of this research that was to investigate the need for the creation of a BBLearn community of practice in the computer department of the public HEI and confirms it.

As per the findings above, this research case study answered the first research question by identifying a list of the anticipated benefits from the creation of the BBLearn CoP. The list included the activities listed in the characteristics of successful CoPs as presented by Wenger (2006). Knowledge sharing, learning from each other, bridging the professional development gaps, open dialogue and increasing BBLearn adoption are among the listed benefits of the BBLearn CoP.

On the other hand, this case study research answered the third research question by confirming that the BBLearn CoP will encourage the computer department faculty to increase their usage of BBLearn. This research revealed that while the faculty of computer department are receiving adequate professional training on BBLearn. The lack of practice has been identified as one of the main reasons for the slow adoption of BBLearn. BBLearn CoP will address this lack of practice by providing a shared space for the faculty to practice the BBLearn features they learned. This confirmed that the creation of a BBLearn Cop will have positive impact the adoption of BBLearn among the computer department faculty. Finally, this case study revealed that the faculty of computer department believe that the BBLearn CoP should be managed by the faculty and sponsor and extremal members are essential to the success of this CoP.

In conclusion, this case study research study explored and investigated the need for the creation of a BBLearn community of practice in the computer department of the public HEI, its anticipated benefits and its positive impact on increasing the adoption of BBLearn among the computer department faculty. Further research is needed to extend the findings of this study to other departments in the public higher education institution where the study took place.

\section{REFERENCES}

Abdullah, F., \& Ward, R. (2016). Developing a General Extended Technology Acceptance Model for E-Learning (GETAMEL) by analysing commonly used external factors. Computers in Human Behavior, 56, 238-256.

Allen, J. F. (1984). Towards a general theory of action and time. Artificial Intelligence, 23(2), 123-154.

Andrea Liberatore, Erin Bowkett, Catriona J. Macleod, Eric Spurr, \& Nancy Longnecker. (2018). Social Media as a Platform for a Citizen Science Community of Practice. Citizen Science: Theory and Practice, 3(1). https://doi.org/10.5334/cstp.108

Blackboard | Education Technology \& Services. (n.d.). Retrieved February 9, 2018, from http://www.blackboard.com/index.html

Cambridge, D., Kaplan, S., \& Suter, V. (2005). Community of practice design guide: A step-by-step guide for designing \& cultivating communities of practice in higher education. EDUCASE Learning Initiative.

Chang, C. K., Chen, G. D., \& Li, L. Y. (2008). Constructing a community of practice to improve coursework activity.(Report). Computers \& Education, 50(1), 235-247. https://doi.org/10.1016/j.compedu.2006.05.003

Cho, H. (2016). Under co-construction: An online community of practice for bilingual pre-service teachers. Computers \& Education, 92, 76-89.

Clarke, L. (2009). The POD model: Using communities of practice theory to conceptualise student teachers' professional learning online. Computers \& Education, 52(3), 521-529. https://doi.org/10.1016/j.compedu.2008.10.006

Coleman, J. S. (1986). Social theory, social research, and a theory of action. American Journal of Sociology, 91(6), 1309-1335.

Cozby, P. (2008). Methods in Behavioral Research (10 edition). Boston: McGraw-Hill Humanities/Social Sciences/Languages.

Creswell, J. W. (2014). Research Design: Qualitative, Quantitative, and Mixed Methods Approaches. SAGE Publications. 
Czerniewicz, L., \& Brown, C. (2009). A study of the relationship between institutional policy, organisational culture and e-learning use in four South African universities. Computers \& Education, 53(1), 121-131.

Daghfous, A., \& Barkhi, R. (2009). The strategic management of information technology in UAE hotels: An exploratory study of TQM, SCM, and CRM implementations. Technovation, 29(9), 588-595.

Dlamini, R. S. (2015). The role of the strategic and adaptive Chief Information Officer in higher education. Education and Information Technologies; New York, 20(1), 113-140. http://dx.doi.org.ezproxy.hct.ac.ae/10.1007/s10639-013-92695

Eckert, P. (2006). Communities of practice. Encyclopedia of Language and Linguistics, 2(2006), 683-685.

Enrollments. (n.d.). Retrieved April 27, 2018, from http://www.hct.ac.ae/en/about/factbook/enrollments/

Goodson, L., \& Phillimore, J. (2004). Qualitative research in tourism: Ontologies, epistemologies and methodologies. Routledge.

Gunn, C. (2010). Sustainability factors for e-learning initiatives. ALT-J, 18(2), 89-103.

Hearn, S., \& White, N. (2009). Communities of practice: Linking knowledge, policy and practice. Overseas Development Institute London (UK).

Jakovljevic, M. (2012). A model of creativity, innovation and invention (MCII) from knolwedge management perspective for interdisciplinary education. Knowledge Management Innovations for Interdisciplinary Education: Organizational Applications by S Buckley: USA: IGI Global Publishers., 66-87. https://doi.org/10.4018/978-1-4666-1969-2.ch004

Kassim, E. S., Jailani, S. F. A. K., Hairuddin, H., \& Zamzuri, N. H. (2012). Information system acceptance and user satisfaction: The mediating role of trust. Procedia-Social and Behavioral Sciences, 57, 412-418.

Kats, Y. (2010). Learning Management System Technologies and Software Solutions for Online Teaching: Tools and Applications: Tools and Applications. IGI Global.

Kirkman, B. L., Mathieu, J. E., Cordery, J. L., Rosen, B., \& Kukenberger, M. (2011). Managing a New Collaborative Entity in Business Organizations: Understanding Organizational Communities of Practice Effectiveness. Journal of Applied Psychology, 96(6), 1234-1245. https://doi.org/10.1037/a0024198

Lave, J., \& Wenger, E. (1998). Communities of practice. Retrieved June, 9, 2008.

Leedy, P. D., \& Ormrod, J. E. (2010). Practical Research: Planning and Design (9 edition). Boston: Pearson.

McDermott, R. (1999). Learning across teams. Knowledge Management Review, 8(3), 32-36.

Mirza, A. A., \& Al-Abdulkareem, M. (2011). Models of e-learning adopted in the Middle East. Applied Computing and Informatics, 9(2), 83-93. https://doi.org/10.1016/j.aci.2011.05.001

NVivo: The Qualitative Data Analysis \& Research Software. (n.d.). Retrieved February 22, 2015, from http://www.qsrinternational.com/products_nvivo.aspxhttp://atlasti.com/

Patton, M. Q. (2001). Qualitative Research \& Evaluation Methods (3rd edition). Thousand Oaks, Calif: SAGE Publications, Inc.

Probst, G., \& Borzillo, S. (2008). Why communities of practice succeed and why they fail. European Management Journal, 26(5), 335-347.

Salmon, G. (2005). Flying not flapping: a strategic framework for e-learning and pedagogical innovation in higher education institutions. ALT-J, 13(3), 201-218.

Shank, G. D. (2005). Qualitative Research: A Personal Skills Approach (2 edition). Upper Saddle River, N.J: Pearson.

Tarhini, A., Hone, K., Liu, X., \& Tarhini, T. (2017). Examining the moderating effect of individual-level cultural values on users' acceptance of E-learning in developing countries: a structural equation modeling of an extended technology acceptance model. Interactive Learning Environments, 25(3), 306-328.

Van Rensburg, G., Botma, Y., Heyns, T., \& Coetzee, I. (2016). Establishing a Community of Practice: from Outsiders to Insiders. Gender \& Behaviour, 14(1), 7028-7039.

Vrazalic, L., Macgregor, R. C., Behl, D., \& Fitzgerald, J. (2009). E-learning barriers in the United Arab Emirates: Preliminary results from an empirical investigation.

Wang, Y.-S., Wang, H.-Y., \& Shee, D. Y. (2007). Measuring e-learning systems success in an organizational context: Scale development and validation. Computers in Human Behavior, 23(4), 1792-1808.

Wenger, E. (2000). Communities of practice: The key to knowledge strategy. In Knowledge and communities (pp. 3-20). Elsevier.

Wenger, E. (2006). Communities of practice: A brief introduction. Retrieved March 26, 2010.

Wenger, E., McDermott, R. A., \& Snyder, W. (2002). Cultivating communities of practice: A guide to managing knowledge. Harvard Business Press.

Yin, R. K. (2013). Case study research: Design and methods. Sage publications. 